\title{
A PRESENÇA DO LAICATO CATÓLICO NO PARANÁ DOS ANOS DE 1920 E 1930*
}

\author{
The presence of Catholic Laity in Paraná in the \\ 1920's and 1930's
}

\author{
Névio de Campos**
}

\begin{abstract}
RESUMO
Este artigo analisa a trajetória, os debates e os projetos dos intelectuais católicos leigos em torno da temática educativa à luz do contexto histórico paranaense, do período de estudo que está circunscrito nas décadas de 1920 e 1930, discutindo o processo de constituição do grupo, as suas interlocuções com as vertentes teóricas e filosóficas em geral, as suas idéias e intervenções culturais, bem como suas relações com o Estado e com os grupos políticos no cenário paranaense desse período. Discorre sobre as contribuições do laicato católico ao projeto romanizador da Igreja Católica e enfatiza que o papel deste grupo foi criar instituições culturais no contexto paranaense, sem esquecer o contexto político-cultural do Brasil e da Europa como pano de fundo de criação do laicato católico. Apóia-se nos periódicos escritos e dirigidos pelo grupo, os quais nos possibilitaram conhecer que a elite intelectual católica leiga estabeleceu instituições culturais onde congregaram os principais intelectuais e lideranças políticas do Estado e da capital que se colocaram a serviço do projeto romanizador da Igreja Católica.
\end{abstract}

Palavras-chave: intelectuais; cultura; formação humana; religião.

* A discussão relativa ao Laicato Católico no Paraná foi tema de minha dissertação intitulada Laicato Católico: o papel dos intelectuais no processo de organização do projeto formativo da Igreja Católica no Paraná (1926-1938), defendida em 2002, no Programa de Pós-Graduação em Educação, na Linha de Pesquisa História e Historiografia da Educação, na Universidade Federal do Paraná, sob orientação do Prof. Dr. Carlos Eduardo Vieira. Este artigo é parte do primeiro capítulo, intitulado "O processo de constituição do laicato católico no Paraná”.

** Professor no Departamento de Teoria e Prática de Ensino (UFPR) e nas Faculdades do Brasil. Mestre e Doutorando em História e Historiografia da Educação. Email: nmestrado@ig.com.br. 


\begin{abstract}
This article analyses the trajectory, the debates and the projects of Catholic intellectuals who are layman about the educative thematic according to the historical context of Paraná, in the study period that is circumscribed between 1926 and 1938, discussing the group constitution process, its interlocution with theoretic and philosophic thoughts in general, its ideas and cultural interventions, as well as its relations to State and Political Groups in the scenery of Paraná during this period. It runs over the contribution of Catholic layman to the romanizing project of Catholic Church and emphasizes that the role of this group was to create cultural institutions in the context of Paraná without forgetting the political and cultural context of Brazil and Europe as a creation support for Catholic Laity. It is based on periodicals written and described by the group, which allowed us to know that the intellectual Catholic layman elite established cultural institutions where the main intellectual and political leads of State and Capital groups, so they placed themselves serving the romanizing project of Catholic Church.
\end{abstract}

Key-words: intellectual; culture; human development; religion.

\title{
Introdução
}

O objetivo deste artigo é analisar a trajetória do grupo intelectual católico no processo de organização e disseminação da cultura, no Paraná, com ênfase no grupo que interveio de forma sistemática e direta nas questões formativas. Em termos ainda mais específicos, visa analisar a trajetória, os debates e os projetos dos intelectuais católicos leigos em torno da temática educacional à luz do contexto histórico paranaense dos anos de 1920 e 1930. Nesse sentido, é fundamental analisar o processo de constituição do grupo, as suas interlocuções com as vertentes teóricas e filosóficas em geral, as suas idéias e intervenções culturais, bem como suas relações com o Estado e com os grupos políticos presentes no cenário paranaense desse período.

O problema central consiste na discussão sobre o papel dos intelectuais católicos leigos paranaenses no processo de organização do projeto formativo da Igreja Católica. Nestes termos, a nossa tarefa será evidenciar em que medida o laicato católico contribuiu com o projeto romanizador da 
Igreja Católica no Paraná. A função desse grupo foi fundamental à igreja, pois nos anos de 1920 e de 1930 o pensamento católico teve forte impacto na cultura paranaense.

A discussão acerca desta problemática está fundamentada na pesquisa empírica nos diversos jornais e revistas criados pelo laicato católico ao longo dos anos de 1920 e 1930, ou seja, nos periódicos Alvor (19351936); A Cruzada (1926-1931); Cruzeiro (1931-1932); O Luzeiro (1937 a 1939); Revista do Círculo de Estudos Bandeirantes (1934-1954). Utilizamos também as Correspondências do Pe. Luiz G. Miele, escritas entre 19291973. É importante ressaltar que parte destas fontes extrapola o período de nossa pesquisa, no entanto, são imprescindíveis à medida que se referem a episódios que ocorreram na temporalidade de nossa investigação.

\section{O processo de constituição do Laicato Católico no Estado do Paraná}

No Estado do Paraná, a organização do grupo católico começou a se definir a partir de 1926, com a criação da União dos Moços Católicos de Curitiba e com o desenvolvimento da imprensa católica dirigida pelos leigos. O ápice desse processo ocorreu no final da década de 1920, com a fundação do Círculo de Estudos Bandeirantes. Nestes ambientes de debate cultural e de formação moral e intelectual foram formalizados os planos de ação deste grupo no Paraná. O laicato católico se articulou em torno destas instituições com objetivos distintos, embora intimamente relacionados, pois na imprensa e na União de Moços Católicos de Curitiba expressava a retórica militante sem se preocupar com o aprofundamento do debate das idéias da Igreja Católica e, no Círculo de Estudos Bandeirantes, postulava a necessidade de aprofundar o debate dos problemas sociais, políticos, filosóficos e religiosos à luz da doutrina católica.

A reação da Igreja Católica assumiu um papel decisivo a partir de 1920, quando a alta hierarquia mobilizou o laicato católico para defender e divulgar os princípios do catolicismo entre os diversos grupos sociais do Brasil. Até então, a Igreja estava se organizando internamente, pois para 
estabelecer o seu programa de reação ao laicismo se fazia necessário criar um clero combatente e comprometido com as diretrizes da romanização. Na década de 1920 foram criados, no Rio de Janeiro, o Centro Dom Vital, a revista A Ordem e na década de trinta a Liga Eleitoral Católica, a Confederação Católica Brasileira de Educação (CCBE). Para atingir este estágio de organização, o grupo que dirigia a Igreja Católica no Brasil se mobilizou desde meados do século XIX com o objetivo de constituir seu grupo para combater os anticlericais e principalmente divulgar aos brasileiros as idéias advindas dos documentos dos pontífices.

Este projeto de organização do clero e do laicato teve presença marcante no Estado do Paraná, começando com a criação da diocese de Curitiba, em 1892, e mais tarde com diversas outras, entre as quais destacamos as de Ponta Grossa e Jacarezinho, bem como a criação de diversas instituições culturais, visando congregar os intelectuais leigos e prepará-los para servir ao projeto romanizador.

O laicato católico paranaense estabeleceu a União de Moços Católicos de Curitiba como um dos primeiros espaços de debate e de mobilização da juventude católica, o qual foi criado em agosto de 1926 por iniciativa do arcebispo de Curitiba e com a colaboração de parte da juventude católica. A fundação desta agremiação possibilitou o começo de um longo processo de encontro e militância da intelectualidade católica paranaense. A partir daí, o grupo passou a manifestar e divulgar continuamente as idéias católicas entre a população deste Estado. Antes disso, a reação católica dependia fortemente das ações do clero. Dito de outra maneira, a reação implementada pela Igreja Católica até o final da década de 1910 estava fundamentada nas forças de alguns padres. No Paraná, a principal liderança católica na virada do século foi o Pe. Desidério Deschand. A rigor, esta foi uma marca do catolicismo brasileiro no final dos oitocentos e nas primeiras décadas dos novecentos.

Os primeiros encontros do grupo católico paranaense expressavam profunda preocupação com o aspecto missionário. Neste sentido, os objetivos consistiam em reunir a mocidade católica para orientá-la nos sãos princípios cristãos e sociais e encaminhá-la na estrada do que denominavam de verdadeiro civismo, propagando a religião católica, defendendo-a em todas as situações e trabalhando em auxílio de todas as obras católicas. Desta forma, a Igreja visava organizar em torno da União de Moços Cató- 
licos de Curitiba um grupo intimamente ligado aos seus valores, capaz de defender e de divulgar a sua doutrina entre os paranaenses. A constituição deste exército exigia a realização de encontros contínuos dos associados, nos quais estavam presentes atividades espirituais e estudos teóricos, bem como momentos de lazer e orientação para o trabalho. Observemos que a ação do grupo católico estava fundamentada nos elementos da espiritualidade, intelectualidade, recreação e do trabalho. O aspecto moral estava presente em todos estes elementos, ou seja, a moral católica deveria nortear as atividades recreativas, bem como o trabalho físico e intelectual do ser humano.

Embora a preocupação primordial da União de Moços fosse com a formação moral dos jovens curitibanos, não estava ausente a necessidade da formação intelectual. Em nosso entendimento, esta instituição indicava a necessidade de estabelecer a formação integral da juventude católica, pois o grupo católico leigo precisava criar espaços de combate aos anticlericais e de divulgação da doutrina católica, além de lugares para estudo e debate intelectual. Para divulgar os princípios católicos, o grupo determinou que o caminho seria promover congressos, retiros espirituais, publicação de obras religiosas, disseminar a ação católica para diversos lugares, inclusive nos meios rurais. Para fomentar o começo da formação intelectual de seus membros, tratou de estabelecer propostas de palestras, de estudos filosóficos, de criação de bibliotecas, além de trabalhar pela fundação de sociedades congêneres, embora não tenha sido possível identificar eventos realizados com preocupação marcadamente intelectual.

Ao lado da União de Moços, o grupo católico paranaense estabeleceu a Revista A Cruzada. No Paraná, entre 1926 e 1939, o grupo católico leigo esteve dirigindo um ou mais periódicos, o que sustenta a tese de que a imprensa católica foi estabelecida como estratégia de divulgação dos princípios da Igreja. O grupo católico afirmava que ao ver “a verdade insolentemente negada e a virtude cinicamente proscrita, não deixará esta revista de levantar sua voz para defender a ambas, alumiando e alentando”. ${ }^{1}$ Portanto, a Revista A Cruzada, criada em 1926, consistiu em forte elemento de divulgação das idéias católicas no cenário cultural paranaense e de contraposição aos grupos alheios ao seu pensamento. Outros periódicos

1 A CRUZADA, março de 1926, p. 1. 
deram continuidade à missão iniciada em 1926, entre os quais destacamos O Alvor, O Cruzeiro, Luzeiro e a Revista do Círculo de Estudos Bandeirantes, que também estavam sob direção do laicato católico paranaense.

Na imprensa católica o grupo disseminava os valores católicos endereçados particularmente ao público culto curitibano. ${ }^{2}$ Nestes espaços não havia interesse em discutir profundamente as questões filosóficas do catolicismo. As mensagens estavam ancoradas num pragmatismo moral cunhado por pensadores conservadores europeus do século XIX.

Estes periódicos passaram a ser porta-vozes da intelectualidade católica que começava a dar os seus primeiros passos em direção à constituição de uma elite preocupada com o aprofundamento teórico das questões políticas, filosóficas, teológicas, científicas e literárias à luz da doutrina católica. O grupo católico entendia que era um dever propagar a boa imprensa, pois se tratava da forma mais rápida de combater a má imprensa, isto é, aquela propagada pelos anticlericais. A imprensa católica se intitulava portadora da boa mensagem, pois pregava que "a boa leitura preserva dos múltiplos erros que envenenam as almas incautas, orna de conhecimentos a inteligência, fortalece a vontade para o bem, robustece a fé, alenta a esperança num prêmio eterno e inflama a caridade para com Deus e para com o próximo; mostra, em uma palavra, o verdadeiro caminho que se deve trilhar”. ${ }^{3}$ Nesta direção, conclamava aos pais de família que se empenhassem pela sã educação de seus filhos, resguardando os princípios do catolicismo. A boa educação, no entendimento do grupo, consistia em reconhecer e em seguir a doutrina estabelecida pela Igreja Católica.

O grupo católico paranaense sabia do papel que a imprensa católica cumpria no projeto de romanização do catolicismo no Brasil, bem como no Paraná. A má imprensa precisava ser combatida. Em Curitiba, os católicos associavam a má imprensa aos jornais ímpios, dirigidos pelos anticlericais declarados (Luz de Krotona), e aos periódicos que se denominavam neutros (Diário da Tarde/A República). Nestes últimos, os anticlericais costumavam escrever artigos que se opunham ao ideário da Igreja Católica. No nosso entendimento, a Igreja acreditava que a imprensa

2 Estamos chamando de público culto curitibano aqueles que liam os periódicos católicos, mas que não participavam dos debates teóricos da Igreja Católica. Eram leitores, portanto, assinavam as revistas ou jornais católicos.

3 A CRUZADA, fevereiro de 1928, s. p. 
católica deveria contribuir com a salvação da sociedade ao divulgar a sua doutrina, ao informar sobre as atividades dos inimigos e sobre os meios de combates já experimentados em diferentes lugares do mundo.

O grupo católico criou, em 1929, o Círculo de Estudos Bandeirantes, o que, em certa medida, representou continuidade das demais instituições estabelecidas nos anos de 1920, pois objetivava também congregar a juventude católica paranaense. Por outro lado, constituiu-se no principal espaço de debate intelectual da filosofia/teologia católica. Este centro cultural foi criado em setembro de 1929, cujo projeto foi idealizado primeiramente por Pe. Luiz Gonzaga Miele, José Loureiro Fernandes e José Farani Mansur Guérios, mas no ato da criação contava com onze fundadores. Este projeto consistiu em estratégia da Igreja Católica, pois “o Círculo teve como principal ideador e fundador o Revmo. Pe. Luiz Gonzaga Miele, então catedrático de filosofia do Internato do Ginásio Paranaense. Professor emérito, dotado de polimorfa cultura, grande espírito de organização e extraordinária capacidade de trabalho, conseguiu logo reunir elementos indispensáveis à fundação deste núcleo cultural”. ${ }^{4}$ Miele estendeu o convite a diversas pessoas de Curitiba para compor o grupo de fundação; não obstante, no início uma pequena parcela participou. Mais tarde, porém, o Círculo contou com significativo número de sócios e participantes. A figura de Miele é descrita pelo grupo católico como principal liderança no processo de criação deste centro cultural, pois se afirmou que "somente a compleição intelectual e moral de um Padre Luiz Gonzaga Miele, modelo do cidadão e do patriota, hércules do pensamento, brilhante talento, inteligência invulgar servida por aprimorada cultura geral e filosófica, (...) ousaria esta 'entrada' pelo inóspito sertão do egoísmo, do utilitarismo e da mediocridade, características de épocas de crise e de decadência”. ${ }^{5}$

O grupo fundador do Círculo de Estudos Bandeirantes ocupava as principais atividades culturais e profissionais da capital paranaense, pois seus integrantes tiveram formação acadêmica nas faculdades de filosofia, engenharia, medicina e direito. Neste aspecto, diferenciava-se dos integrantes da União de Moços Católicos de Curitiba, bem como dos que dirigiam a imprensa católica. Esta condição legitimava a atuação do Círculo e o carac-

4 REVISTA DO CÍRCULO DE ESTUDOS BANDEIRANTES, 1934. p. I.

REVISTA DO CÍRCULO DE ESTUDOS BANDEIRANTES, 1943. p. 552-553. 
terizava como centro cultural marcadamente preocupado com a formação intelectual de seus membros.

O projeto de fundação do Círculo contou com a colaboração de outras personalidades curitibanas, como por exemplo, Manoel Ascensão Fernandes, Afonso de Camargo e Caetano Munhoz da Rocha, aos quais o Conselho do Círculo conferiu, posteriormente, o titulo de sócios beneméritos. Os dois últimos nomes dirigiram por longo tempo o Estado do Paraná; portanto, da esfera estatal contribuíram com o projeto da Igreja Católica. Esta situação caracterizava a aproximação que houve entre poder religioso e poder civil no Estado do Paraná. Na década de 1920, por oito anos seguidos, o Paraná foi governado por Caetano M. da Rocha, cuja administração esteve marcadamente interessada em servir aos projetos do catolicismo. Certamente que a aliança entre Estado e Igreja interessava a ambos, pois o Estado buscava legitimar seu poder com o aval da Igreja, e a Igreja esperava que o Estado se tornasse um instrumento de colaboração no processo de constituição de seus valores na sociedade brasileira.

A colaboração de diferentes intelectuais foi fundamental para constituição do projeto do Círculo de Estudos Bandeirantes. Ao grupo católico "o CEB seria uma sociedade cultural, não aberta e declaradamente religiosa, confessional. Poder-se-ia nas reuniões ventilar qualquer assunto, mesmo religioso, mas dentro dos princípios da ortodoxia religiosa, filosófica, científica, etc. Não teria o CEB nem poderia ter por sua específica finalidade 'converter' a quem quer que fosse”. ${ }^{6}$ Portanto, o Círculo de Estudos Bandeirantes nasceu com o objetivo de promover estudos filosóficos, científicos, literários e religiosos à luz da doutrina católica, o que indica que sua preocupação se dirigia para a formação intelectual dos seus integrantes, visando formar uma elite intelectual que fosse capaz de dar sustentação teórica ao projeto romanizador no Paraná. Ao contrário da imprensa católica e da União de Moços Católicos, o Círculo cumpria a tarefa de reunir os principais intelectuais paranaenses para debater os problemas teóricos à luz da doutrina neotomista. O grupo que dirigia o Círculo raramente fazia uso dos periódicos católicos que pregavam e divulgavam os seus princípios com um forte teor moral. Esta postura indica que o laicato católico agiu em dois campos: uma parcela do grupo agia na imprensa com a pretensão de

6 Correspondência do Pe. Miele a Loureiro Fernandes, 06 jul. 1956. 
divulgar a doutrina da Igreja Católica; outra se dedicava aos estudos no interior do Círculo, no qual a preocupação essencial era se dedicar ao estudo das questões políticas, filosóficas, teológicas, científicas e literárias.

Os integrantes do Círculo de Estudos Bandeirantes foram os principais representantes do laicato católico no Paraná. Em outras palavras, este grupo que começou a se encontrar no final da década de 1920 em torno deste círculo cultural representava, de acordo com os termos de Loureiro Fernandes, a vanguarda da intelectualidade católica. Isso significa que estes intelectuais do interior do Círculo sistematizavam as idéias católicas e, particularmente, as divulgavam entre uma parcela de paranaenses, pois à medida que se sistematizavam programas de estudo e debate, o número de integrantes do Círculo crescia, o que indica que houve grande investimento na divulgação e mobilização da juventude paranaense/curitibana para assumir o projeto católico romanizador. Na década de 1930, foi a partir do Círculo de Estudos Bandeirantes e da imprensa católica que o laicato católico se estruturou e se lançou em disputa pela formação moral e intelectual da juventude curitibana/paranaense.

No interior do Círculo de Estudos Bandeirantes, foram discutidos os pressupostos da formação católica, pois “contra essa vulgaríssima mediocridade que é preciso combater, ergue-se o Círculo de Estudos visando à formação intelectual de seus membros, desfazendo preconceitos, resolvendo dúvidas, respondendo consultas, esclarecendo, enfim, e armando os seus sócios para as conquistas pacíficas da verdade”. ${ }^{7}$ Os diferentes saberes foram discutidos, inclusive o conhecimento científico foi tratado como um saber importante para a vida humana. No entanto, diziam que o conhecimento da ciência pressupunha concepções antropológica, filosófica e metafísica do ser humano.

O debate em torno do conhecimento filosófico não implicou na suspensão da discussão sobre os saberes científicos. No primeiro decênio de atividades do Círculo de Estudos Bandeirantes, inúmeros temas foram discutidos pelos intelectuais paranaenses, a saber: debate sobre questões relacionadas à estética, à filosofia política, à ética e moral, à metafísica, à religião, às ciências humanas, às ciências naturais, ao direito, à literatura. Entre 1929 e 1931, Pe. Luís Gonzaga Miele discutiu sobre monismo mate- 
rialista e ciência moderna. Nicolau dos Santos Neto se debruçou sobre o belo, moral e estética e percepção estética. No período 1935-1936, foi realizado o primeiro curso de filosofia para os integrantes do Círculo, coordenado pelo Pe. Jesus Ballarin. Neste período, também, Manuel de Oliveira Franco Sobrinho discorreu sobre a personalidade e a obra de Jacques Maritain. Entre 1938 e 1939, Bento Munhoz da Rocha Neto debateu sobre a classificação tomista das ciências. Este intelectual já havia feito em 1935 uma conferência sobre o tomismo. No período de 1933-1934, Liguaru Espírito Santo apresentou seu estudo sobre o Cardeal Mercier. Entre 1932-1933, Flávio S. de Lacerda discutiu sobre a física moderna. Estes temas indicam que a intelectualidade paranaense incluiu a filosofia em seus debates; no entanto, sua inclusão não implicou no abandono das contribuições das ciências modernas, mas o postulado da harmonia entre a filosofia tomista e a ciência.

À medida que o grupo paranaense se constituía e se fortalecia, a Diretoria do Círculo de Estudos sentia a necessidade de dispor de um curso de filosofia tomista para os integrantes desta sociedade cultural. Este curso foi ministrado nos anos de 1935 e 1936 pelo Pe. Jesus Ballarin, cuja formação recebera na Universidade de Cervera (Lérida) e ao chegar ao Brasil exerceu atividade de professor de Filosofia no Seminário Cordimariano, a princípio em Rio Claro, no Estado de São Paulo, e posteriormente em Curitiba, nos anos acadêmicos de 1929-36, tendo sido lente de várias disciplinas: Metafísica, Teodicéia, Filosofia Moral e Social, Sociologia, Filosofia Natural, Psicologia e História da Filosofia. Para o encerramento do curso ministrado no Círculo, houve sessão extraordinária, estando presentes o bispo de Curitiba, Dom Ático Eusébio da Rocha e o Cônsul da Bélgica, Marcel Godefroid. A conferência de encerramento, intitulada $O$ tomismo e o neotomismo e o Cardeal Mercier, versava sobre o papel da filosofia católica no pensamento moderno. Para o autor, “a doutrina de Santo Tomás de Aquino produzira sempre frutos opimos e sazonados, uma vez que seja tratada com a difusão e a clareza devidas, investigando e analisando todas e cada uma das suas partes. Todas elas, numa harmonia admirável, constituem um corpo único de doutrina, mas não é possível que um só professor as possa penetrar e abranger todas". ${ }^{8}$ É interessante a representação que o autor cria a respeito da filosofia tomista ao dizer que teoria produzirá sempre

8 REVISTA DO CÍRCULO DE ESTUDOS BANDEIRANTES, 1939. p. 27. 
frutos abundantes e excelentes, isto é, com qualidade. Portanto, não produzirá frutos pútridos e amargos. Ballarin apresentou a teoria tomista como doutrina profícua para compreender os problemas atuais, desde que seja estudada na sua totalidade. Não obstante, asseverava que a compreensão teórica desta filosofia somente se daria à medida que os estudos assumissem uma dimensão coletiva. Em nosso entendimento, esta passagem estabeleceu um argumento favorável aos católicos, pois em tese a doutrina tomista era suficientemente capaz de dar conta dos problemas teóricos modernos. Porém, havia um condicionante, qual seja, desde que compreendida integralmente. Ora, se a filosofia tomista fosse negada por algum grupo, devia-se ao fato de não ter sido compreendida pelo mesmo. Esta afirmação que está implícita na passagem pode ser lida como uma crítica à Filosofia Positiva, que postulou o valor da ciência em contraposição à teologia.

Esta passagem de Mercier deve ser compreendida no contexto geral da época, qual seja, Leão XIII havia ordenado que as instituições católicas de ensino voltassem a adotar a filosofia tomista como doutrina orientadora de seus ensinamentos. Em 1880, o pontífice solicitou ao Cardeal Goosens, Arcebispo de Malines, que fosse criado na Universidade Louvaniense um curso especial de filosofia tomista. O responsável pelo primeiro curso de filosofia tomista foi o Cardeal Mercier. Daí o sentido de seu pedido para que a hierarquia da Igreja constituísse um grupo de pesquisadores e professores da filosofia tomista. Ballarin, usando as palavras de Wulf, um dos principais discípulos do Cardeal, afirmava que "Mercier foi o iniciador principal da renascença do Tomismo; chamou a atenção de todos sobre o Neotomismo, elevando-o até ocupar um lugar entre os sistemas a serem escolhidos por qualquer espírito avisado do século XX”. ${ }^{9}$

Mercier foi uma das referências neotomistas para o laicato católico no Paraná, além de Jacques Maritain. Este último era considerado pelo grupo católico o maior neotomista da França daquela época. O curso ministrado por Ballarin procurou estabelecer entre os intelectuais católicos paranaenses uma compreensão ampla da filosofia tomista a fim de que se entendesse a relação entre a filosofia/metafísica de São Tomás de Aquino e o conhecimento científico. 
Segundo Ballarin, Mercier indicava que filosofia moderna se caracterizava pela independência excessiva de qualquer autoridade doutrinária e pelo menosprezo completo da tradição científica. O autor pôs em cena dois projetos em disputa, bem como campos do conhecimento disputando espaços no mundo moderno. De um lado, o discurso religioso/teológico de cunho tomista e, de outro, o discurso científico laico. É a luta pelo monopólio do poder de fazer ver e de fazer crer, de fazer conhecer e de fazer reconhecer, de impor a definição legítima das explicações do mundo social. Neste aspecto, o curso de filosofia do Círculo estava profundamente vinculado ao projeto católico estabelecido pela Igreja no Paraná. Não bastava caracterizar o pensamento católico; era fundamental desqualificar a filosofia moderna. A imagem que os católicos criaram da filosofia moderna era extremamente pejorativa. Ela foi responsabilizada pela separação entre a filosofia e a teologia, a filosofia e a ciência, a verdade e a realidade, a prática e a teoria. Imagine a cena: separar a verdade da realidade - isso quer dizer que a partir da época moderna não houve mais verdade, isto é, a filosofia moderna criou uma verdade artificial ou falsa verdade, não correspondente à realidade. Para o pensamento católico tomista, a verdade dependia da teologia; portanto, não havia possibilidade de a ciência produzir a verdade independentemente da filosofia católica. Para os católicos, apenas a ciência moderna negava a convivência pacífica entre o conhecimento racional e o conhecimento revelado. Na concepção do grupo católico, não existia desconformidade entre esses dois saberes; ao contrário, eles se complementavam. A ciência moderna acreditava que o seu papel era cuidar do seu objeto de estudo, sem a preocupação de discutir questões filosóficas ou metafísicas. Esta compreensão científica foi sintetizada na Filosofia Positiva de Comte, que postulava que a ciência devia se preocupar com aquilo que estava na realidade empírica, ou melhor, com o que podia ser observado. O grupo católico não discordava deste papel atribuído à ciência. O que ele questiona era a postura dos cientistas quando se propunham a fazer ciência e não se ocupavam de discutir as questões filosóficas/ metafísicas que estavam presentes nas suas metodologias científicas.

É possível afirmar que o curso de filosofia ministrado nos anos de 1935-1936, no Círculo de Estudos Bandeirantes, pelo Pe. Jesus Ballarin, concretizou o ideário do grupo católico leigo que começou a se formar, em 1926, com a constituição da Revista A Cruzada e com a criação da União 
dos Moços Católicos de Curitiba. O laicato católico consolidou-se institucionalmente, em 1929, com a fundação do Círculo de Estudos Bandeirantes, pois para este grupo somente com uma sólida formação tomista se chegaria, no Estado do Paraná de tão promissor futuro, à constituição da formação intelectual dos católicos, preconizada pelo Cardeal Mercier e, no Brasil, postulada por Alceu Amoroso Lima. Nestes termos, o curso de filosofia de 1935-1936 evidencia que o grupo católico acreditava que com esta formação intelectual seria possível arrefecer a filosofia moderna, que negava o poder da doutrina católica, e restaurar a filosofia tomista, garantindo à Igreja Católica a sua presença no campo intelectual, moral, social e político na sociedade brasileira/paranaense do século XX.

\section{Conclusões}

A Igreja Católica começou a implementar seu projeto ultramontano, no Paraná, a partir de 1892, com a criação da Diocese de Curitiba. O primeiro bispo, D. José Camargo de Barros, iniciou este trabalho, seguido pelos seus sucessores que, nos primeiros vinte anos do século XX, investiram na constituição de um clero comprometido com a doutrina romanizadora, trazendo da Europa inúmeras congregações religiosas femininas e masculinas.

A estratégia de criação do laicato católico foi pensada pela alta hierarquia da Igreja, pois os documentos oficiais ressaltavam o sentido da constituição daquele grupo nos diferentes países e cidades. Neste artigo, analisamos o papel dos intelectuais católicos leigos no processo de organização do projeto educativo da Igreja Católica no Paraná, discutindo o processo de constituição do laicato católico paranaense, bem como suas atividades formativas no cenário cultural curitibano.

Neste sentido, destacamos que o laicato católico se constituiu com a criação da União de Moços Católicos de Curitiba, com o estabelecimento da imprensa católica e a fundação do Círculo de Estudos Bandeirantes. Indicamos também que os periódicos e o Círculo de Estudos Bandeirantes constituíram estratégias estabelecidas pelo laicato para se organizar como grupo intelectual e como espaços privilegiados para estudar e divulgar a 
doutrina católica, bem como se contrapor ao grupo anticlerical que estava presente na capital paranaense. A rigor, os periódicos, exceto a Revista do Círculo de Estudos Bandeirantes, tinham a preocupação de divulgar entre os leitores paranaenses a moral católica; o Círculo de Estudos Bandeirantes cumpria a tarefa de aprofundar as questões teóricas à luz da doutrina romanizadora da Igreja. Ou seja, o laicato católico agia em duas direções, isto é, dos periódicos procurava atingir um público genérico da cidade de Curitiba; do Círculo estabelecia uma meta restrita às elites intelectuais, ou seja, aquelas que freqüentavam as academias e tinham condições de produzir discussões teóricas mais aprofundadas.

Enfim, indicamos que o grupo católico teve papel importante no projeto da Igreja Católica no Paraná, pois estabeleceu instituições culturais onde se congregaram os principais intelectuais e lideranças políticas da capital e do Estado. Portanto, o laicato católico aglutinou em torno dos periódicos e, particularmente, do Círculo de Estudos Bandeirantes, a elite intelectual/dirigente paranaense, que de seus postos contribuiu com o projeto romanizador, garantindo a presença da cultura católica na formação nos modos de pensar e agir, bem como nas instituições públicas e privadas do Estado. 